\title{
Psychological Factors Analysis in Using of Water Resources Based on The Social Psychology of Chinese College Students
}

\author{
Yue $\mathrm{Wu}^{1}$ \\ Xi'an University of Technology, Xi'an, Shaanxi, China \\ wuyue@xaut.edu.cn
}

Keywords: Chinese college student, Using of water resources, Psychological factors, Group Society.

Abstract. The researchers think more about the control factors except themselves, and ignore their own psychological factors in the aspect of water-saving. From the perspective of psychology, the paper discusses the Chinese college students about the group psychological factors, the popular psychological factors, the social consumption psychological factors and internal individual psychological factors in using of water resources. And it puts forward the corresponding measures. They are expected to meet the behavioral standards required by the country, the government, the social, to establish a water-saving society at last.

\section{The significance of psychological factors in using of water resources about the Chinese college students}

Human which is the only rational creature on the earth, developing to today, has to face the problem - saving the earth resources. Especially the water resources, it is the basic material need of the human beings to maintain and development, it also is the foundation of realizing the sustainable development of economic and social. For the water resources is severe shortage, and use water efficiency is lower, advocating the construction of water-saving society is the important way to realize sustainable development and utilization of water resources. At present, the colleges and universities is the main user of water resources, the water is mainly used for life of the students and public facilities water. From the survey statistics of some colleges and universities ${ }^{[1][2][3][4]}$, water consumption for life per student is $180 \sim 300 \mathrm{~L} /($ people.d). It is 2 times than that of water for residential use.

The author invested on the situation of water use by the way of questionnaire on university, the number of total survey questionnaire was 2000, the number of return questionnaire was 1977 , the valid questionnaires was 1880.The research results showed that the water consumption was 2001/(people,d)per students. It is considerable for a city in the northwest of China. The case is showed in the following table1.

Table 1

\begin{tabular}{|l|l|}
\hline Content & Water Consumption Rate (\%) \\
\hline Bathing & 45.28 \\
\hline Flush the toilet & 32.04 \\
\hline Washing clothes & 11.53 \\
\hline Washing face & 10.17 \\
\hline Washing tableware & 0.2 \\
\hline Others & 0.78 \\
\hline Total & 100 \\
\hline
\end{tabular}

Universities had to take a variety of methods to control consumption of water resources for college students, such as investing funds in water-saving equipment, strengthening the propaganda of water-saving and so on, but the effect was not significant, even still visible to the phenomenon of wasting water. Someone question that College students should be high- quality and ability to accept knowledge, why is this case exist? 
In fact, except the factors such as management, moral, culture, Human beings with complicated psychological factors played also an important role in the using of water resources.

In the past, the water-saving researchers tended to ignore the person's own subject factors, especially the human behavior rule of psychological factors. On the condition of the water resources being scarce, although applying for the system design, moral consensus, culture guidance to assure it reasonable and efficiency, the water user's self-discipline consciousness and self-discipline action is the fundamental way ${ }^{[5]}$. So, the problem of water-saving about Chinese college students is the psychological problems firstly. College students are crowd aggregation which is made of mankind individual. It is this group and the psychological characteristics of individuals that dominate drastically their behavior of water, especially the generation of self-discipline behavior. Therefore, analysising China college student of psychological level about water-use behavior and putting forward the corresponding countermeasures from the perspective of psychology, educators make college students form water-saving self-discipline behavior to meet the standards required by the government and social behavior, to establish water-saving society finally.

\section{The psychological factors analysis of using of water resources based on the social psychology of Chinese college student}

The using of water resource seems to be an individual behavior, but the behavior itself has close relationship to social and behavioral results. Chinese college students, in particular, their cultural background values the eastern philosophy, and at this age and college students is in important period of self-identity, and the period of others and the social-identity, they value the others' evaluation and approval for them. Under the action of social groups and social scene, the individual's perception of things themselves, emotion and emotion will be changed, individual behavior and decision will change with it. Therefore, this article attempts to analysis students' psychological factors in using of water resource from the perspective of social psychology.

The group psychological factors analysis about Chinese college students in using of water resources

Every individual of people exists in a group which is in a complex social relation, it forms a special social psychological phenomenon, such as group atmosphere, team morale, cohesion and social encouraging and fretting, cooperation and competition, and so on. These phenomena tend to not appear in individual activities, only to occur in the group and to be experienced by individual, and form a special group psychology .If ,in a group, the decision makers and leaders of the group grasp the group's psychological phenomenon well, they can affect the members of the group psychological state, and improve their sense of belonging and sense of responsibility, forming good social effect and morale and making their members clear the direction of the behavior and activity, consistent with the leader's intent. On the contrary, if decision makers and leaders of the group do not know something about the group psychology, or the development of the group psychological the is bad, they will not improve the members a sense of belonging and responsibility, not forming the morale, sometimes even forming negative influence, it will make the members of group psychological conflict, its consistency and common behaviors and activities targeted change, his target is invalid. Chinese college students group has its special psychological characteristics compared with other social group. This group has a high knowledge level and good life quality in China, that is a number of people with high quality, high knowledge level. They have concerned high about social problems, and have good understanding to accept new things, and adapt to it well; But on the other hand, for their culture is deep inside information, the identity desire is strong, and the using water behavior is more influenced by culture and identity, soit will be shown that its concept is affected by group easily during it takes shape, and it's not easy to change once they are formed. This special ability tests the capacity of group leader. 


\section{The mass psychological factors analysis about Chinese college students in using water resources}

Social psychologists pointed out that the individual which is in a group often is pressured by population unconsciously, and consistent with the most people in perception, judgment, belief and behavior, this is conformist mentality phenomenon. It is a relatively common psychological phenomenon mixed with personal characteristics, and the phenomenon is not equal to the loss of standpoint and the principle. Although some people feel the group orientation do not agree with personal ideas, but in order to preserve our sanity, to avoid conflict, the people agree still with the views of the majority of people against one's will. It is the so-called conformity or go with the flow. This is the so-called phenomenon of obedience. For example, the famous "bystander effect". "Bystander effect" is a phenomenon of the number of bystander increasing, and the altruistic behavior decreasing. This is due to the number of bystanders increasing, people will have responsible to spread a certain social behavior, the phenomenon will have inhibitory effect on people's public welware behavior.

Water use behavior of Chinese college students are inevitably followed such psychological law of the masses. Especially the college students' self-consciousness is very high, they care about their evaluation from society, and hope to get others' recognition, when their behavior does not been recognized by others and society, they often prone to deviate in consciousness and behavior. When a lot of people in the campus has act to save water, it can affect the individual, so that the individual will not consciously to join; When most people in the campus shut their eye to the opened water bridle, the other people will likely be indifferent, this phenomenon is not very relevant to the good or bad of moral consciousness, sometimes just scene effect, such as obedience phenomenon, if social ethos and social scene advocate of saving water, so even if some people in the group don't like, but he or she has to subordinate to the overall need of groups.

The social consume psychological factors analysis about Chinese college students in using of water resources

Consumer psychology, also belonging to the scope of social psychology in generalized, is all kinds of psychological phenomenon of the consumer in business ${ }^{[2]}$. Consumers belong to different social groups, their psychological also will get its own psychological phenomenon and group social psychological phenomenon. So, a consumer's consumption behavior reflects not only its own psychological characteristics, also social psychology and behavior patterns of his group. Water-use behavior of Chinese college students, as a kind of water consumption, also has its consumption psychology.

First of all, students will also form some kinds of otherwise dual contradiction psychological tendencies about some waste and save. On the one hand, seeking profit psychological exits in the water consumption wide spread, and hopes to profit in it. On the other hand, the consumers pay money on water, so they pay less for using less water, intend to save. Even now in some universities water-use for students is free, after all, college students go to school by paying tuition. So, the contradictions between seeking profit mentality and environmental mentality exist too. Second, college students' need of water consumption has great flexibility and hierarchy. Because they carry out the consumption activities of some college student psychological phenomena inevitably, liking following the fashion, comparisons mentality, conformity mental ${ }^{[6]}$. About water needs, they not only have lower levels material physical needs, but also have the high-level needs, such as respect and social status, the self-value, etc. ${ }^{[7]}$

The individual internal psychological factors analysis about Chinese college students in using of water resources

Although social psychology attaches great importance to the individual's group influence on human psychology and behavior, but in the same group, because the difference of people's internal psychological factors, people will inevitably produce different reaction. It is a person's intrinsic psychological factor. The social psychology pay attention to individual psychological factors by which individual can make psychological reaction in stable. Chinese college students in using of 
water resources is the behavior of each individual college students. The behavior is affected inevitable by the individual itself cognition, attitude, related things, need, personality factors and behavioral characteristics. For example, some students think that the earth's water resource is very rich, and inexhaustible in supply, and it is always available for use. They do not think about water-saving in the usual life. For example, some students think that water-saving is other people's business, as long as their comfortable, how many doesn't matter, or he doesn't care about human and social development. They would not have water-saving behavior. On the contrary, although some students themselves have the water demand, they have the deep understanding to the precious water resources, and concern about the development of society and human. They know themselves a member of the society, so he would have to pay attention to save during using water. This is the role of individual psychological factors in the using water resources.

In addition, the behavior of the individual can be divided into conscious and unconscious behavior. Some individual's unconscious behavior under the attention may be developed to conscious behavior. If the conscious behavior can also be developed to the unconscious behavior by training. For example, a student, who don't pay attention to his own using water condition originally, may form conscious water-saving behavior, identification producing after water conservation education. And such a conscious behavior of water-saving can develop to a kind of habit behavior, namely develop to an unconscious of water-saving behavior.

\section{Social psychology measure of the water-saving behavior about Chinese college students}

\section{Starting with the group mind, to establish good water-saving oriented, forming water-saving cohesion among Chinese college students group}

As the previous analysis, China's college students, as a society group, have their own group psychology, so, from the perspective of the group mind, educators use a variety of group psychological phenomenon to cause mentality of water-saving, water saving behavior, so as to form a harmony on campus. The educators should use the group psychology, especially pay attention to the role of group leader. This includes the school, the school leader, also the student's teacher and grade's student cadres, and even school each teacher, because teachers' words and deeds always plays a subtle role on students. From the following aspects: first, leaders should improve their own quality, and start from themselves, and practice what they preach, for college students in groups to provide good water-saving oriented. Leader behavior in the group can improve his control on college students within the group, and make them establish benign thinking preference, make them feel the confidence of the leader at the same time, and encourage them to improve the quality and efficiency. Second, the leader should actively strengthen the group goal and group norms to make college students in the groups form a unified water-saving ultimately. When necessary, the leader set up the system to provide security. Third, the leader should know the needs of the college students in the group in time, and communicate with him in time according to the specific situation to solve the problem, so as to enhance their sense of belonging and sense of responsibility, to produce the good social effect and morale, to form a strong cohesion of water-saving in group.

Applying for social situation, to form saving-water campus atmosphere, improving the consciousness of water-saving and the affective commitment among Chinese college students

The conscious behavior comes from the good conscious. In the first place, the main body of using water have reasonable consciousness about water-use for forming rational utilization of water resources. Not only that, this conscious includes affect's commitment, such as loving for the earth, human and other life, and the common anxiety about water resource being scarce during the course of development of human society, and the convergence attitude of water-saving. In addition, in terms of the individual's personality, the water-use conscious is the psychological characteristics which is showed when the people is stability and reality attitude and the habit of the behavior. Only the necessity, importance of water-use has a deep understanding, and after forming the habit of water-saving, students develop the stable personality psychological about water-saving. Therefore, to 
increase college students' conscious of water-saving and affective commitment, the educators should strength the propaganda and education to form deference level atmosphere of water-saving in the whole campus, and to feel the social scene of water saving behavior. College students are high IQ, and their mastering and applying knowledge rate is high. Educators can use normal classroom, and teach them the water resources lacking status and reasons, so that they produce consciousness of water crisis; Through systematically clarifying the relationship of the water, earth and human society, educators make the students produce affective commitment; Educators can also have psychological training to students about water-saving behavior, help them form good water-saving behavior. College students are active, and like to participate in the campus activities. Educators can mobilize all issues of common concern by organizing various campus cultural activities relating to the water-saving, forming cherish water resources of the social scene everywhere, and a common water-saving behavior eventually.

Applying for the mass psychological phenomenon, to form psychological interaction consciously, to adjust Chinese college students' psychology of behavior about water resource

There are a lot of social interaction psychological phenomenon in social psychology. It is of very subtle psychological reaction among individuals in the group. The reaction can make the interacts between the individual and individual, and can influence each other. About the water-saving problems in college students, educators use or holding-up some social psychology interaction phenomenon in group, consciously adjust the college students' psychology and behavior of water-use. For example, educators make students produce the interaction social psychology phenomenon consciously or unconsciously by propaganda and education. Eventually, the goal of water-saving is reached. In addition, by setting up the typical method and using the model, college students psychological and behavioral is affected. Such as the advanced number of water-saving is given a certain economic reward every year or every quarter. On the one hand, making the campus public opinion, inducting the group thinking preference, educators form the social supervision, so as to affect college students' behavior. On the other hand, inducing the water saving society altruistic behavior, educators reduce the generation of the "bystander effect". Educators can educate the advanced students among the college students, such as the class leaders, activist of party application, utilizing the organization measures, subject to psychological, and asking for them start water-saving behavior and re-using the group psychology to influence others to join water-saving action. In addition, Educators can put forward a small water-saving demand to college students by "on the threshold technology" firstly, then increase the requirement of water saving gradually. According to the different situation of different colleges and students, educators brought about the incessant of the water-saving behavior by the "in front of the technology," similar to the "low technology", and so on. According to the laws of the consumer psychology, educators advocate green consumption to change the unreasonable need in using of water resources about the Chinese college students Consumption demand is the main influence factors controlling consumer behavior. There is some unreasonable phenomenon of water consumption among college students. It is unreasonable water demand which is not consistent with the social development goal. Some people think that the induction and inhibition on the consumption of people rely mainly on economic means, especially the price adjustment. The calculation of water cost and the results about water-user psychological test show that when water expense ratio accounts for $2 \%$ of household income, water user can use water reasonably; When water expense ratio accounts for $4 \% \sim 5 \%$ of household income, it produces a great impact on the psychology of residents, so they can save water ${ }^{[8]}$. But such people don't meet their psychology of benefit, that is to say, they are no " suffer losses " feeling for more using water, and no " gain extra advantage by unfair means" for less using water. In order to solve this problem, school should use "the method of alkaline stimulation", and raise the price to achieve "the less water, the lower the price, the more water price is higher " way. Let people who use more water loss of psychological balance feel " suffer losses ". Let people who use few water get mental satisfaction feel " gain extra advantage by unfair means ", so that consumers are conscious and willing to save water 
automatically, so as to achieve the goal of control water consumption. It a good method of paying for the water consumption, even implementing with ladder-like water price.

Since the birth of human being, the human being is the consumer of earth resources. Today, the earth's resources are no longer maintain high consumption of human beings. To sustain the development of human society, mankind must change the previous way of life and consumption patterns, it is more effective way. This kind of change, of course, do not lower the quality of human life, but a transformation of consumption ethics. Green consumption is a kind of consumption concept for putting forward to the human society sustainable development. Green consumption, it is a kind of new, healthy consumption pattern. It is a kind of consumer behavior pattern ${ }^{[9][10]}$ within the framework of sustainable development, for saving resources and protecting the environment. Therefore, green consumption pattern should vigorously be promoted for college students, which is in accordance with the group psychological characteristics of innovation, fashion and personality.

\section{Conclusions}

The research on water-saving should think about the factors, such as management, humanities, moral, at the same time, also should pay attention to the person's own subject factors, especially psychological factors of human behavior ruler. Because human beings is complicated psychological factors which has also played an important role in using of water resources. We can try to start from the measures above mentioned, and ultimately achieve national standards required by the government, social norms, to establish water-saving society.

\section{References}

[1]JialiangLi,LinWang,ShuiboWu, Water consuming and saving mode in university of Qingdao, Water resources protection,88-89,2007(3)

[2]WanxiaFu,JunhaiLi, The measure and Analysis of water consumption of university student dormitory in Beijing,Journal of Beijing Institute of Civil Eng.and Architecture,35-36,2004(6)

[3] CongnaDong, The Construction of Water-Saving Model at Hengshui University, Journal of Hengshui University,110-112,2013(10)

[4] ChanghongWu, RonghuaWu,,Water-saving and thinking of college construction practice, water resources management,18-19.2013(11)

[5]ShuchengWang. The report of constructing water-preservation society on the congress of committee of experts in magazine China Water.2005-6-23

[6]HaoyueLiu, Social Psychological Analysis of Contemporary College Students' Abnormal Consumption, Journal of HUBEI Correspondence Unniversity,41-42,2015(23)

[7]JinmeiHao,WenmingWang,Socio-Psychological Analysis on the Consumption of Current College Stedents, Huazhong Normal University Journal of Postgraduates, 120-121,2009(3)

[8] ZhongqingHan, Promoting Water-saving measures and building a economized water-efficient society[J].China Water Kesources,2003,484(5):11-12

[9]JianengYang, College students' green consumption problems and countermeasure analysis[J],Manager' Journa,201604:1011

[10] MinLiu,JunshanMu, Green-consumption and green-marketing[M],Guangming Daily Press,2004 